\title{
Commentary: Direct spinal cord perfusion: You need it when you need it
}

\author{
Muhammad Aftab, MD, and T. Brett Reece, MD
}

\footnotetext{
From the Division of Cardiothoracic Surgery, Department of Surgery, Anschutz Medical Center, University of Colorado, Aurora, Colo.

Disclosures: Authors have nothing to disclose with regard to commercial support.

Received for publication April 20, 2019; accepted for publication April 22, 2019; available ahead of print May 31, 2019

Address for reprints: T. Brett Reece, MD, 12631 E 17th Ave, MS C310, Aurora, CO 80045 (E-mail: brett.reece@ ucdenver.edu).

J Thorac Cardiovasc Surg 2019;158:e131-2

$0022-5223 / \$ 36.00$

Copyright (C) 2019 by The American Association for Thoracic Surgery

https://doi.org/10.1016/j.jtcvs.2019.04.064
}

Spinal cord protection from ischemia remains the most critical aspect for successful outcomes after open or endovascular thoracic aortic surgery. Selective reimplantation of intercostal arteries during thoracoabdominal aortic aneurysm (TAAA) or descending thoracic aortic aneurysm repairs is a common surgical strategy for preserving the spinal cord perfusion. However, this cuff of native aortic tissue is at risk of late aneurysmal degeneration. Coselli and colleagues ${ }^{1}$ reported late repair failure in $88(2.6 \%)$ of 3309 TAAA repairs over a median follow-up of 6 years. Of these, 33 patients ( $1 \%$ ) developed patch aneurysm. Kulik and colleagues ${ }^{2}$ reported a $7.1 \%$ (11/155 patients) incidence of intercostal patch aneurysm requiring open or endovascular repair after a mean duration of 5.3 years from the initial TAAA/descending thoracic aortic aneurysm repair. Among these, 45\% (5/11) had Marfan syndrome. The optimal way to address with this complication is not known but can be dealt with in a variety of approaches. The use of separate grafts to the patch has facilitated exclusion with either thoracic endovascular aortic repair or plugging, but the need to preserve flow to these critical vessels is even more unknown than primary preservation at the time of TAAA repair. This technique certainly adds breadth to potential options for perfusion maintenance that would be less feasible, or impossible, with sewing the island to the aortic graft directly.

This report describes an innovative approach of preserving spinal cord blood supply with intercostal stent grafting and periscope thoracic endovascular aortic repair for an intercostal loop graft aneurysm. ${ }^{3}$ The authors' method to manage this challenging problem is unique. This patient had a loop graft attachment of 3 intercostal arteries. One of these was particularly hypertrophied and provided significant spinal collaterals. The intercostal implantation provides spinal cord protection during the most vulnerable perioperative period.

Numerous reports have demonstrated a successful endovascular repair of late intercostal patch aneurysms. Special attention should be paid to assess the patent, large intercostal

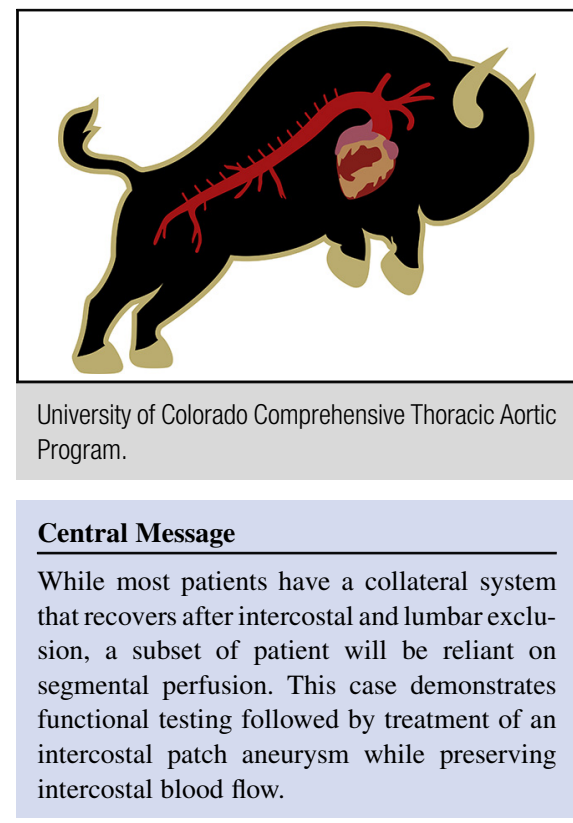

See Article page e127.

vessels when treating these patch aneurysms. These can potentially be noncollateralized intercostal arteries, which remain crucial to spinal cord perfusion even many years after the initial TAAA repair. The authors ingeniously used a combination of angiography, a trial of provocative balloon occlusion of loop graft, with assessment of motor-evoked potentials to determine their operative strategy.

The attention to spinal cord detail in this case was absolutely required to prevent paraplegia. The methodology of provocative testing of spinal cord function allowed tailoring the procedure based on the need for flow preservation. Then, the much less-invasive approach to continued direct spinal cord perfusion was employed with functional maintenance of motor function. Importantly, the procedure did not preclude the ability to proceed with open revascularization and exclusion if needed. The authors should be commended for their perseverance in pursuit of the best approach for this individual patient. The majority of centers may ignore the potential risk of paraplegia without adequate bailout options for this scenario by excluding flow to these vessels from the onset.

This case highlights the role of neuromonitoring and the use of novel techniques to repair various complex aortic pathologies. These new methodologies can be performed 
safely when done with strict attention to preserving the principles of spinal cord preservation.

\section{References}

1. Coselli JS, LeMaire SA, Preventza O, de la Cruz KI, Cooley DA, Price MD, et al. Outcomes of 3309 thoracoabdominal aortic aneurysm repairs. J Thorac Cardiovasc Surg. 2016;151:1323-37.
2. Kulik A1, Allen BT, Kouchoukos NT. Incidence and management of intercostal patch aneurysms after repair of thoracoabdominal aortic aneurysms. J Thorac Cardiovasc Surg. 2009;138:352-8.

3. Tjaden BL Jr, Estrera AL, Afifi RO. Intercostal artery stent grafting to prevent paraplegia during endovascular treatment of an intercostal loop graft aneurysm after thoracoabdominal aortic aneurysm repair. J Thorac Cardiovasc Surg. 2019; 158:e127-30. 